\title{
A SCAR marker for the analysis of chloroplast DNA from different cultivars of Cornus officinalis
}

\author{
L. Zhang', R.X. Liu' ${ }^{1}$, J. Wang' ${ }^{2}$, T. Zhang' ${ }^{2}$, J. Li' ${ }^{2}$, J.H. Shi', B.Y. Kang' ${ }^{1}$ and \\ S.Q. Chen ${ }^{2}$ \\ ${ }^{1}$ Department of Pharmacy, First Affiliated Hospital of Henan University of Traditional \\ Chinese Medicine, Zhengzhou, China \\ ${ }^{2}$ College of Pharmacy, Henan University of Traditional Chinese Medicine, \\ Zhengzhou, China \\ Corresponding author: S.Q. Chen \\ E-mail: suiqingchen@yeah.net
}

Genet. Mol. Res. 14 (4): 17170-17181 (2015)

Received August 6, 2015

Accepted October 28, 2015

Published December 16, 2015

DOI http://dx.doi.org/10.4238/2015.December.16.17

ABSTRACT. The aims of this study were to establish a random amplified polymorphic DNA (RAPD) fingerprint database of chloroplast DNA (cpDNA) from different cultivars of Cornus officinalis and to convert RAPD markers to sequence characterized amplified regions (SCAR) markers. A method of extraction was established that was suitable for obtaining cpDNA from samples rapidly dried in silicone; an RAPD fingerprint database was built; and the genetic distance between samples was used as statistical clustering variables for calculating DICE genetic similarity coefficients and for building a kinship tree chart. RAPD markers were converted to SCAR markers to design specific primers, and samples from $C$. officinalis cultivars, plants of the same family, and its adulterants, were used for amplification and identification. Fifteen amplified primers with stable polymorphisms were screened for amplification of 130 copies of materials. In total, 57 sites were achieved, 40 of which were polymorphic, and the polymorphic rate was up to $70.18 \%$. A genetic tree was built based on 
seven cultivars. SCAR markers of $C$. officinalis cpDNA were successfully converted into RAPD markers. cpDNA samples from hawthorn, C. officinalis, Cornus wood, and grape were used for SCAR amplification, and their bands were distinctly different. In conclusion, SCAR markers and cPDNA may be used for research on $C$. officinalis and its adulterants, and the results may provide a basis for identifying germplasm and screening fine varieties at $a$ molecular level.

Key words: Cornus officinalis; Chloroplast DNA; DNA sequence; SCAR marker

\section{INTRODUCTION}

Cornus officinalis refers to the dried, ripe, and stoneless fruit of Cornus officinalis Sieb. et Zucc., which is a member of the Cornaceae plant family. This fruit can tonify the liver and kidney and arrest seminal emission, and is mainly used against vertigo, tinnitus, and waist and knee pains. Recent studies have shown that $C$. officinalis can regulate the immune system and has significant pharmacological effects (Es Haghi et al., 2014; Han et al., 2014; Sozański et al., 2014). This fruit is native to Henan, Shaanxi, and Zhejiang provinces in China. According to the shape, size, weight, color, and other traits of fruits of different cultivars, our scholars have conducted a preliminary study on intraspecific variations, and divided fruits into seven fruit types. In the cylindrical type, the fruit are cylindrical or oblong, with both ends slightly truncated, and most "stone mill dates" in Henan province belong to this type. The long cylindrical type consists of elongated cylindrical fruits, and has several variations. In addition, some of fruits are less bend, and are known as "long form dates" in Henan, while some are slightly curved, with a slightly pointed or pointless top, known as "horse teeth dates" in Henan areas and "banana dates" in Shaanxi areas. The oval type has oval fruits and exists in several variations, with an inconsistent maturity period and different surface colors of fruits. The main fruit type in Henan and Zhejiang areas is the long pear-shaped type, which is characterized by long pearshaped fruits with a slightly narrow base, called "rice dates". These are mostly distributed in Shaanxi areas and less so in Henan areas. The spindle-shaped type is characterized by oval fruits that have slightly pointed ends, and most "millet dates", as they are called in Henan, are of this kind with ovalto-oblong fruits. The short cylindrical fruit type, called "pearl red", has short cylindrical, short oblong and nearly-circular fruits and is mostly distributed in the Henan area short pear-shaped type with pear-shaped fruits, is mostly distributed in Shaanxi areas and less in Henan areas. Identification of morphological, microscopic, and phytochemical characteristics of these fruits is incomplete (Li et al., 2009). Domestic research has focused on their chemical composition and pharmacological effects, without further study of variation in the cpDNA. Thus, this research is not conducive for germplasm conservation and exploitation of $C$. officinalis. The $c p D N A$ of some higher plants contains variations, and many species have varying degrees of intraspecific cpDNA. It is important to correctly estimate and understand intraspecific variations in cpDNA (Wang et al., 2004; Kozyrenko et al., 2009). cpDNA sequences have been used as important markers in systematic research and have shown superiority in medicinal plant research (Hosokawa et al., 2005; Zou et al., 2015). Therefore, 130 C. officinalis specimens from Henan, Shaanxi, and other main origins were collected in this experiment and subjected to cpDNA extraction. After the establishment of SCAR markers, the identification of $C$. officinalis and its adulterants provides a molecular basis for germplasm identification and for the screening of fine varieties. 


\section{MATERIAL AND METHODS}

\section{Extraction of cpDNA}

Leaves (1.5-5 g) were fast dried in silicone overnight at $4^{\circ} \mathrm{C}$, rinsed, drained, and subjected to midrib removal. Leaves were then shredded, placed in a mortar, and ground in 10\% PVP powder and cold extraction buffer $\mathrm{A}$ ( $50 \mathrm{mM}$ Tris- $\mathrm{HCl} \mathrm{pH}=3.6,25 \mathrm{mM}$ EDTA, 1.25 M NaCl). After filtrating through 8-10 layers of sterile muslin, the filtrate was centrifuged at $3000 \mathrm{rpm}$ at $4^{\circ} \mathrm{C}$ for $10 \mathrm{~min}$ (high-speed refrigerated centrifuge KDC-160HR, HKUST Innovation Co., Ltd., Hefei, China). The supernatant was discarded, gently suspended in $10 \mathrm{~mL}$ buffer $\mathrm{B}(50 \mathrm{mM}$ Tris- $\mathrm{HCl} \mathrm{pH}=3.6,25 \mathrm{M}$ EDTA, 1.25 M $\mathrm{NaCl}, 10 \mathrm{mM} \beta$-mercaptoethanol, and $200 \mu \mathrm{L} 10 \mathrm{mM} \beta$-mercaptoethanol was added before use), and the precipitate was centrifuged at $3000 \mathrm{rpm}$ at $4^{\circ} \mathrm{C}$ for $8 \mathrm{~min}$. The supernatant was discarded and the precipitate was rinsed with butter $B$ and placed into $2.5 \mathrm{~mL} \mathrm{~B}$ butter without $\beta$-mercaptoethanol, 19 $\mu \mathrm{L}$ DNase I, and $1 \mathrm{~mL} \mathrm{MgCl}(1 \mathrm{M})$ in an ice bath for $1 \mathrm{~h}$. The reaction was terminated following the addition of $200 \mu \mathrm{L}$ EDTA. The mixture was centrifuged and the supernatant was discarded. After the addition of refrigerated extraction buffer $\mathrm{C}(0.35 \mathrm{M}$ sorbitol, $100 \mathrm{mM}$ Tris- $\mathrm{HCl} \mathrm{pH}=8.0,5 \mathrm{mM}$ EDTA), the precipitate was incubated on ice for $10 \mathrm{~min}$, and then centrifuged at $3000 \mathrm{rpm}$ for $10 \mathrm{~min}$ at $4^{\circ} \mathrm{C}$. The supernatant was removed, and the remaining precipitate contained the purified chloroplast. The optical density of the supernatant was then measured with a spectrophotometer.

\section{Purification of cpDNA}

The precipitate was place into $10 \mathrm{~mL}$ buffer $\mathrm{D}(50 \mathrm{mM}$ Tris- $\mathrm{HCl} \mathrm{pH}=8.0,25 \mathrm{mM}$ EDTA), and the mixture was suspended. in $1 / 20$ volume of $10 \%$ sodium dodecyl sulfate (SDS), $1 / 5$ volume $10 \%$ sodium dodecyl ammonia sodium, and $1 / 200$ volume $10 \mathrm{mg} / \mathrm{mL}$ proteinase $\mathrm{K}$, and then 100 $\mu \mathrm{L} \beta$-mercaptoethanol was added, the mixture was mixed well by shaking and incubated for $3 \mathrm{~h}$ at room temperature under continuous shaking. The mixture was extracted three times with an equal volume of chloroform: isoamyl alcohol (24:1) and the supernatant was added to I/I0 volume $0.2 \mathrm{M} \mathrm{NaAc}$ and 2.5 volumes of precooled absolute ethanol overnight at $-20^{\circ} \mathrm{C}$. The mixture was centrifuged at 12,000 rpm for $15 \mathrm{~min}$ and the precipitate was collected, washed with $70 \%$ ethanol, and left at room temperature for $15 \mathrm{~min}$. The precipitate was centrifuged at 12,000 rpm for $10 \mathrm{~min}$, air-dried, and dissolved in $1 \mathrm{~mL}$ TE. Next, $1 / 100$ volume of $5 \mathrm{mg} / \mathrm{mL}$ RNA enzyme was added and the samples were incubated for $0.5 \mathrm{~h}$ at $37^{\circ} \mathrm{C}$ before the addition of $1 / 200$ volume proteinase $\mathrm{K}(10$ $\mathrm{mg} / \mathrm{mL}$ ). The samples were incubated for $\mathrm{I} \mathrm{h}$ and then the mixture was subject to extraction with chloroform:isoamyl alcohol (24:1), and deposited in ethanol. The precipitate was washed with $70 \%$ ethanol and pumped in a vacuum. The cpDNA precipitate was dissolved using $50 \mu \mathrm{L}$ deionized water. After further purification with a UNIQ-10 column plant genomic DNA extraction kit (SK1203, Sangon Co., Shanghai, China), samples were used immediately or stored at $-20^{\circ} \mathrm{C}$.

\section{Electrophoresis and purity determination}

The total DNA of $C$. officinalis was extracted, and $10 \mu \mathrm{L}$ cpDNA extract was subjected to electrophoresis (Sanheng multi-purpose electrophoresis DYY-III-12B, Beijing, China), and stained with $0.5 \mathrm{ng} / \mathrm{mL}$ ethidium bromide (EB). Next, gels were placed under a UV light (A600nm UV spectrophotometry photometer, Shanghai, China), and analyzed with a gel analysis system (AmpGene, Dingyong Science and Technology Co., Ltd., Beijing, China). Identification of total DNA 
and $\mathrm{cpDNA}$ enabled the cpDNA purity and its content to be determined to confirm the quality of the proposed sample.

\section{Establishing a RAPD reaction system}

A 25- $\mu \mathrm{L}$ reaction system was chosen to optimize the RAPD reaction conditions based on previous work (Comes and Abbott et al., 2000; Esselman et al., 2000; Bautista et al., 2001; Lu et al., 2002; Collins et al., 2003; Uzonur et al., 2012; Xin et al., 2014).

\section{Template concentration}

The template was diluted 10-fold and the additional amount was set to 1.5, 2.0, 2.5, 3.0, 3.5, $4.0 \mu \mathrm{L}$. Template concentration was determined based on the amplification results.

\section{$\mathrm{Mg}^{2+}$ concentration}

Totals of 2.0, 2.5, 3.0, 3.5, and $4.0 \mu \mathrm{L} \mathrm{Mg}{ }^{2+}$ (25 mM, Sangon Co., Shanghai, China) were included in the reaction and the optimum reaction concentration was determined.

\section{dNTP concentration}

dNTPs (2.5 mM, Sangon Co., Shanghai, China) were diluted 4-fold and the additional amount was set to $1.5,2.0,2.5,3.0$, and $3.5 \mu \mathrm{L}$ respectively. The optimum concentration was determined based on the amplification result.

\section{Buffer concentration}

The additional amount of 10X PCR buffer (Sangon Co., Shanghai, China) was set to 1.5, $2.0,2.5,3.0$, and $3.5 \mu \mathrm{L}$ respectively. The optimum concentration was analyzed and determined.

\section{Primer concentration}

The primer (Sangon Co., Shanghai, China), with 2 OD values, was formulated as $2 \mathrm{M}$. The additional amount was set to $1.5,2.0,2.5,3.0$, and $3.5 \mu \mathrm{L}$ respectively. The final reaction concentration was analyzed and determined.

\section{Taq DNA polymerase concentration}

Various amounts of Taq DNA polymerase (0.25-5 U of $5 \mathrm{U} / \mu \mathrm{L}$, Sangon Co., Shanghai, China) were added to the $25-\mu \mathrm{L}$ reaction system in order to determine the optimal concentration. The additional amount was set to $0.5,0.75,1.0,1.5$, and $2.0 \mu \mathrm{L}$ respectively. The final reaction concentration was analyzed and determined.

\section{Temperature cycle parameter}

The temperature cycle parameters were established as follows: predenaturation for $5 \mathrm{~min}$ 
at $94^{\circ} \mathrm{C}$, denaturation for $1 \mathrm{~min}$ at $94^{\circ} \mathrm{C}$; refolding for $1 \mathrm{~min}$ at $50^{\circ} \mathrm{C}$, elongation for $1 \mathrm{~min}$ at $72^{\circ} \mathrm{C}$; polishing for $5 \mathrm{~min}$ at $72^{\circ} \mathrm{C}$. All processes included 35 cycles with the fastest heating and cooling. According to those factors that had the most impact on amplification, refolding temperatures of $30^{\circ}$, $35^{\circ}, 38^{\circ}, 40^{\circ}$, and $50^{\circ} \mathrm{C}$ were investigated, with other conditions remaining unchanged.

\section{Establishing a RAPD fingerprint database}

\section{Screening for primers and RAPD amplification}

Quality templates that were extracted and amplified in large amounts were required to screen primers, and PCR amplification was performed under optimal conditions. Multiple experiments were performed until all primers generated strong and clear bands after three consecutive amplifications. The bands were present in the same number, were of high stability, and showed good polymorphisms. In total, 130 samples were amplified using the above primers.

\section{Construction of a kinship tree chart and establishment of an RAPD fingerprint database}

Valid loci were detected and calculated in multi-amplified fragments, and electrophoretic bands with the same mobility were used as homologous sites. Strong bands were marked as 1 , and weak and no band were marked as 0 . A data matrix with 0,1 , and bands of every primer was used as an RAPD fingerprint database of cpDNA obtained from seven cultivars. The genetic distance between samples was as statistical clustering variables, and SPSS 16.0 software was adopted to calculate DICE genetic similarity coefficient. The between-groups linkage clustering method was used to construct a kinship tree chart.

The similarity coefficient calculation formula (Dice coefficient) was as follows: $F=2 \mathrm{NAB} /$ $(\mathrm{NA}+\mathrm{NB})$; genetic distance $=1-\mathrm{F}$.

Where, NA and NB represent the number of bands of genotype A and B (or individuals) respectively, while NAB represents the number of mutual bands of $A, B$. cpDNA from seven cultivars was amplified using the screened primers, and the results were visualized on gel images. Valid loci were detected and calculated in multi-amplified fragments, and electrophoretic bands with the same mobility were used as homologous sites. The strong bands were marked as 1 , and weak and no band were marked as 0 . A data matrix with 0,1 , and bands of every primer was used as an RAPD fingerprint database of cpDNA obtained from seven cultivars.

\section{Conversion of RAPD markers to SCAR markers}

Owing to polymorphism or specific bands generated by random primer amplification PCR (e.g., RAPD, AP-PCR), SCAR technology is more repeatable and generates data that are more intuitive than that produced by RAPD.

\section{Establishment of SCAR marker}

RAPD screening was performed and those primers showing high stability and higher polymorphism were selected with random primers (S-series and W series, Shanghai Sangon). Primers that could produce polymorphic and specific bands from the amplification of cpDNA 
from seven cultivars were selected. After continuous repetition of the RAPD reaction, primers that were able to stably maintain band specificity entered the next SCAR-labeled reaction in order to obtain the specific RAPD marker. Recycling for UNIQ-10 column DNA gel extraction kit SK1132 (Sangon Co., Shanghai, China) was for preparation of competent cells (high efficiency competent cell preparation kit, Sangon Company). After connection and transformation, cpDNA was cloned (PUCm-T vector PCR product cloned kit SK2213, Sangon Co., Shanghai, China) and DNA sequencing (Takara Bio Inc.) was performed. According to the cpDNA sequence with RAPD markers at both ends, Primer Premier (V5.0) software was used to design and synthesize primers (Sangon Co., Shanghai, China). Based on the established $25-\mu \mathrm{L}$ reaction system used in RAPD analysis and the reaction system in SCAR markers and ITS sequence analysis of different cultivars in laboratory, after trial and error combined with the characteristics of its own in this study (Bashir et al., 2014; Ryuk et al., 2014), the optimum SCAR-PCR reaction conditions (mainly annealing temperatures) of each specific primer, were established. After cpDNA samples from seven cultivars were amplified, primers were identified and cpDNA with a SCAR marker was achieved.

\section{RESULTS}

\section{cpDNA extraction method}

The optical density of the supernatant was measured with a spectrophotometer. No absorption value was obtained within the range $259-290 \mathrm{~nm}$, indicating that relatively pure chloroplasts were obtained that did not contain a mixture of mitochondrial and nuclear DNA. Results obtained by electrophoresis showed that the extracted cpDNA was significantly different from the total DNA, which indicated that cpDNA was successfully extracted. The $O_{260}$ and $O D_{280}$ values of samples were measured with a UV spectrophotometer. Results obtained for four samples were randomly selected and used to calculate the average value, with the maximum $\mathrm{OD}_{260}$ being 0.638 and the minimum being 0.117 . According to the sample concentration $=\mathrm{OD}_{260} \times 50 \mu \mathrm{g} / \mathrm{mL} \mathrm{x}$ dilution multiple, the yield of total DNA was $351-2049 \mu \mathrm{g} / \mathrm{mL}$, while the $\mathrm{OD}_{260} / \mathrm{OD}_{280}$ ratio was 1.60 . This indicates that this method is optimal for the extraction of cpDNA from rapidly dried samples.

\section{RAPD analysis}

A 25- $\mu$ L RAPD reaction system was established using the following conditions: template DNA (the original extract was diluted with 10-fold) $3.0 \mu \mathrm{L} ; \mathrm{Mg}^{2+}(25 \mathrm{mM}) 3.0 \mu \mathrm{L} ; 10 \mathrm{X}$ PCR buffer $2.5 \mu \mathrm{L}$; dNTP $(2.5 \mathrm{mM}) 3.0 \mu \mathrm{L}$; primer $(2 \mu \mathrm{M}) 2.5 \mu \mathrm{L}$; Taq enzyme $(5 \mathrm{U} / \mu \mathrm{L}) 1.0 \mu \mathrm{L}$; $\mathrm{ddH}_{2} \mathrm{O} 10.0$ $\mu \mathrm{L}$. Optimum temperature cycle parameters were as follows: predenaturation for 5 min at $94^{\circ} \mathrm{C}$, denaturation for $1 \mathrm{~min}$ at $94^{\circ} \mathrm{C}$; refolding for $1 \mathrm{~min}$ at $50^{\circ} \mathrm{C}$; elongation for $1 \mathrm{~min}$ at $72^{\circ} \mathrm{C}$; polishing for $5 \mathrm{~min}$ at $72^{\circ} \mathrm{C}$. The cooling time from $94^{\circ}-35^{\circ} \mathrm{C}$ was set to $1 \mathrm{~min}$, and the heating time from $35^{\circ}-$ $72^{\circ} \mathrm{C}$ was set to $1 \mathrm{~min}$.

A RAPD fingerprint database was established as shown in Figure 1. In total, 57 sites was obtained from the bands generated by 15 primers, of which 40 were polymorphic, and the polymorphic rate was as high as $70.18 \%$. This indicated that the samples had good genetic diversity. The W92205 primer generated the most polymorphic loci with the maximum detection efficiency. It had five polymorphic loci and the polymorphic rate was as high as $83.33 \%$. The $\$ 35$, S90, and S479 primers each generated five loci, four of which were polymorphic, and the polymorphic rate was $80 \%$. The S1142, S1323, and S1432 primers each generated four loci, of which three were 
polymorphic, and the polymorphic rate was $75 \%$. The S512, S92208, and S92210 primers each generated three loci, of which two were polymorphic, and the polymorphic rate was $66.7 \%$. Both $\mathrm{S} 49$ and S91842 primers each generated four loci, of which two were polymorphic. Both S63 and S328 primers each generated two loci, of which one was polymorphic. These results provide information for the further development of specific primers that could be used to identify these seven cultivars.

A kinship tree chart of the seven cultivars was constructed as shown in Figure 2.

Spindle-shaped type fruit was found to be a category on its own. The cylindrical and short cylindrical types were placed together in a class, which had the furthest kinship from the others. The long pear-shaped and short pear-shaped types had the closest genetic relationship, while the long cylindrical and oval types had the closest relationship. These four types formed a class. The genetic relationship of seven cultivars can be observed in the tree chart. The long cylindrical and oval types formed the first class, followed by the long pear-shaped and short pear-shaped types. These two classes got into one, and then it and spindle-shaped type combined one class. Cylindrical and short cylindrical types were in one class, and along with other fruit types, was clustered into one category.

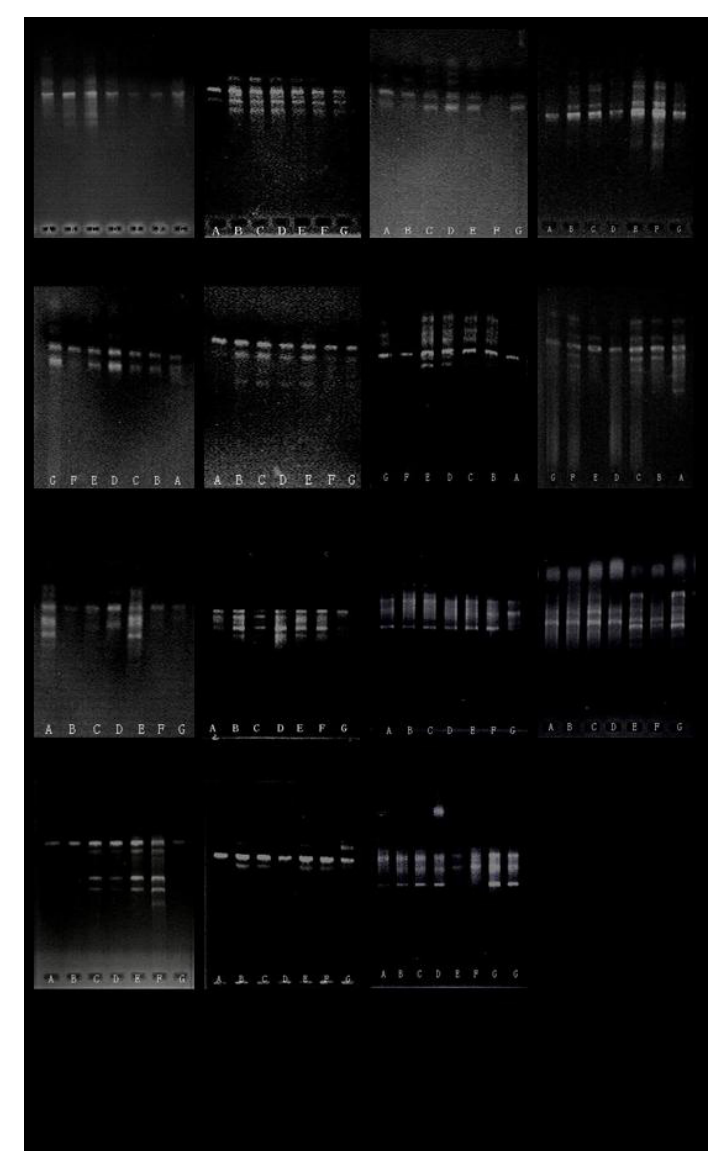

Figure 1. Amplified bands obtained from seven cultivars using 15 primers. S35, S49, W92205 etc. are the primers. A: cylindrical fruit type, B: long cylindrical fruit type, C: oval fruit type, D: long pear-shaped fruit type, E: spindle-shaped fruit type, F: short cylindrical fruit type, G: short pear-shaped fruit type. 


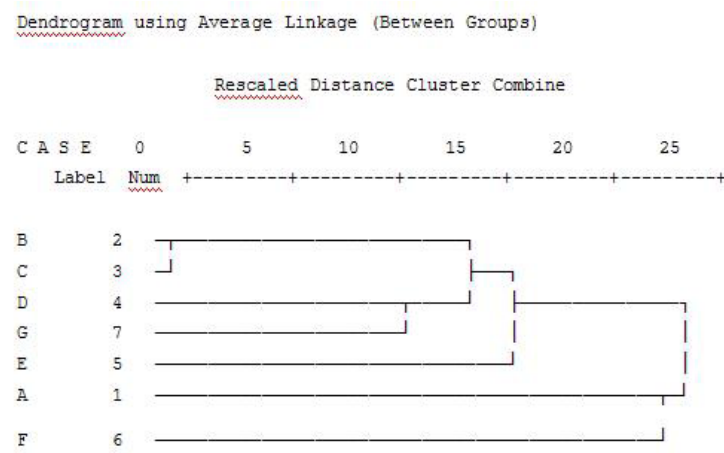

Figure 2. Kinship tree chart for seven cultivars of Cornus officinalis. A: cylindrical fruit type, B: long cylindrical fruit type, C: oval fruit type, D: long pear-shaped fruit type, E: spindle-shaped fruit type, F: short cylindrical fruit type, G: short pear-shaped fruit type.

\section{SCAR marker transformation}

After screening, the specific bands were cloned and sequenced, and a 1102-bp band was achieved using ST479 (Figure 3). Two pairs of SCAR specific primers were achieved, which are shown in Table 1. These results show that the specific fragments can be used as SCAR marker of cpDNA amplified from different cultivars of $C$. officinalis, and plants of the same family, such as Cornus wood and Dendrobenthamia, and its adulterants, such as hawthorn and grapes using the selected primers.

After trialing different experimental conditions, a PCR reaction system was achieved using several common primers. The optimum PCR reaction system was as follows: template DNA (the original extract was diluted 20-fold) $10.0 \mu \mathrm{L}$; $\mathrm{Mg}^{2+}(25 \mathrm{mM}) 6.0 \mu \mathrm{L}$; 10X PCR buffer $5.0 \mu \mathrm{L}$; dNTP $(2.5 \mathrm{mM}) 6.0 \mu \mathrm{L}$; primer $(10 \mu \mathrm{M})$ (an equal amount of $3.0 \mu \mathrm{L}$ of forward and reverse primers); Taq enzyme $(5 \mathrm{U} / \mu \mathrm{L}) 2.5 \mu \mathrm{L} ; \mathrm{ddH}_{2} \mathrm{O} 14.5 \mu \mathrm{L}$, in a final volume of $50 \mu \mathrm{L}$. The final cycle parameters were as follows: predenaturation for $8 \mathrm{~min}$ at $94^{\circ} \mathrm{C}$, denaturation for $1 \mathrm{~min}$ at $94^{\circ} \mathrm{C}$; refolding at $45^{\circ} \mathrm{C}(\mathrm{ST} 479 \mathrm{C})$ or at $55^{\circ} \mathrm{C}$ (ST479E); elongation for $1.5 \mathrm{~min}$ at $72^{\circ} \mathrm{C} ; 40$ cycles, polishing for $10 \mathrm{~min}$ at $72^{\circ} \mathrm{C}$. Amplification products were subjected to electrophoresis in 1X TAE buffer on $1.5 \%$ agarose gels. Gels were then stained with $0.5 \mu \mathrm{g} / \mathrm{mL}$ EB and images were obtained.

As shown in Figure 4-5, cpRNA samples from hawthorn, C. officinalis, Cornus wood, and grape were used for SCAR amplification with the SCAR primer ST479T based on specific bands of the ST479 sequence (Figure 4). The results showed that a single band was achieved from cpDNA amplification of $C$. officinalis, and 2-4 bands were achieved from hawthorn, grapes, and Cornus wood, and this was used for the identification of $C$. officinalis. cpRNA samples of seven cornus cultivars, Cornus wood, Dendrobenthamia, grape, and hawthorn were performed for SCAR amplification using the SCAR primer ST479E based on specific bands of the ST479 sequence (Figure 5). The results showed that cpDNA obtained from seven cultivars generated a single PCR product, and the size of the band was consistent with that of the original cpDNA obtained with RAPD markers. The bands of $C$. officinalis $c p D N A$ were distinct from those of Cornus wood, Dendrobenthamia, grape and hawthorn cpDNA, which indicated that identification of cornus and its adulterants can be performed using the ST479E primers. 


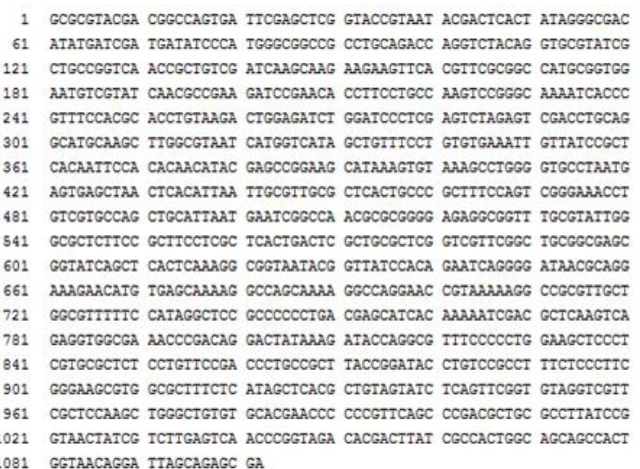

Figure 3. Whole ST479 sequence.

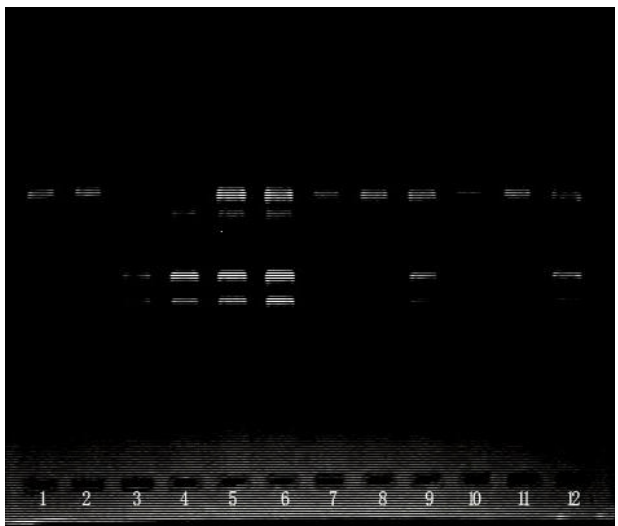

Figure 4. Specific bands obtained by ST479C amplification. Lanes 1-2: Cornus officinalis, lanes 3-4: hawthorn, lanes 5-6: grape, lanes 7-8: C. officinalis, lane 9: Cornus wood, lanes 10-11: C. officinalis, lane 12: Cornus wood.

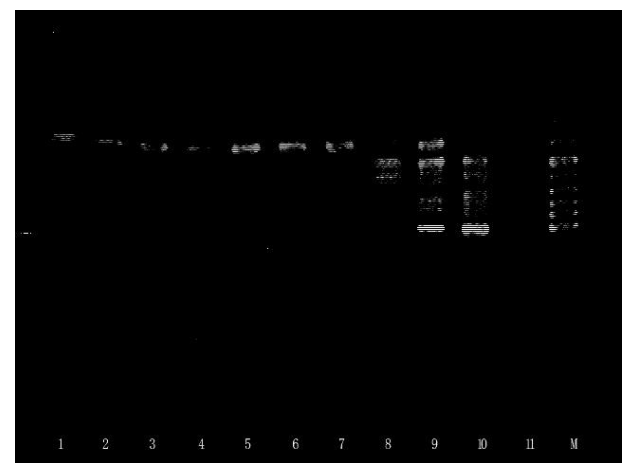

Figure 5. Specific bands obtained byST479E amplification (DNA marker 100-1000 bp). Lanes 1-7: Cornus officinalis (1-7 refers to A-G fruit type respectively), lane 8: Cornus wood, lane 9: Dendrobenthamia, lane 10: hawthorn, lane 11: grape. 
Table 1. SCAR-specific primer sequences.

\begin{tabular}{ll}
\hline Primer number & Primer sequence \\
\hline ST479C (forward) & 5' AGCATAAAGTGTAAAGCC 3' \\
ST479C (reverse) & 5' GGTGTCTTAGTCCTCTAT 3' \\
ST479E (forward) & 5' TAAGAGTACCTCCTGACAA 3' \\
ST479E (reverse) & 5' GAGTGCGACATCGTAGAGTC 3' \\
\hline
\end{tabular}

\section{DISCUSSION}

Many researchers have identified traditional Chinese medicine with molecular markers, such as Andrographis paniculata (Ding et al., 2015), Cordyceps (Feng et al., 2009), and fritillary (Xin et al., 2014). With the development of molecular techniques based on DNA, cpDNA has shown superiority in medicinal plant research, and it has been widely applied to the study of identification and quality evaluation of medicinal plants. cpDNA can be used to identify species of medicinal plants and their mix adulterants, and has the potential for broad application in the geoherbalism of Chinese medicinal herbs, the ecological diversity of medicinal plants, and the source of new drugs. Due to large intraspecific variations generated during long-term application and cultivation. RAPD analysis is used for cpDNA identification of different cultivars and for research and study of their kinship. Following analysis of the genetic relationships among all varieties, and the establishment of a RAPD fingerprint database of cpDNA from cornus cultivars, polymorphism in $C$. officinalis cultivars was discovered.

Current methods used to extract cpDNA have been improved, but most are only applicable to fresh materials. Many samples are required and experimental materials are collected from different habitats and species and analyzed in molecular pharmacognosy research. In order to make use of materials that are taken conveniently, leaves rapidly dried in silicone were used in the present study. Compared with the extraction methods used for young leaves, the generation of more secondary metabolites and degradation occur when using leaves rapidly dried in silicone, which adds a degree of difficulty to the experiment. We have access to a lot of literature detailing different approaches to cpDNA extraction. Improved methods of extracting and purifying cpDNA from rapidly dried leaves were able to obtain a satisfactory result, indicating that the leaves had no effect on the subsequent experiments. Therefore, cpDNA extraction and amplification can be carried out with preserved samples. This improved method can be used in general laboratories, and the resulting DNA is well adapted to cpDNA molecular biology research. Therefore, applying cpDNA to molecular identification techniques used on Chinese medicine herbs is possible.

This study showed that there was a good correlation between the results from RAPD analysis and the current status of $C$. officinalis cultivation. The amplification spectra of cpDNA from different fruit types indicated that non-polymorphic bands were specific to all $C$. officinalis. The present results show that the resolution between cpDNA sequences was good; therefore, RADP was appropriate for use as a molecular marker in Chinese medicine herbs. In this study, the genetic distance between samples as statistical clustering variables, and SPSS 16.0 software was adopted to cluster analysis. Next, a kinship tree chart was established. As shown in the tree chart, the spindle-shaped type fruit was a category on its own, and the long cylindrical and oval type fruits formed a class. Next, the long pear-shaped and short pear-shaped types formed a class, as did the cylindrical and short cylindrical types. This was consistent with the growth and distribution of $C$. officinalis. The spindle-shaped type approximated wild cornus, and along with other plump fruit types clustered into one category with some hybrid varieties. These results show that this 
was due to the long-term cultivation process of artificial selection. Driven by economic benefits, herbalists always choose the plump fruit type. Due to the communication in remote breeds and lack of purification breeding, hybrid varieties are generated

SCAR marker sequences were determined in this study. Therefore, the use of appropriate reaction conditions together with other markers enabled the relative position to be determined through conventional PCR. In addition, this can be used as the positioning mark and the data for establishment of physical map to provide a scientific basis on the development of cpDNA research and on better development, utilization and protection of its germplasm.

In conclusion, the results of this study show that cpDNA can be used to differentiate cornus from its cultivars and related species of the same family from adulterants. Searching for cpDNAspecific RAPD bands in every Cornus fruit type is needed by further screening of random primers. Specific SCAR markers for each fruit type will be explored in the future.

\section{Conflicts of interest}

The authors declare no conflict of interest.

\section{REFERENCES}

Bashir KM, Awan FS, Khan IA, Khan Al, et al. (2014). Identification and authentication of Rosa species through development of species-specific SCAR marker(s). Genet. Mol. Res. 13: 4130-4139.

Bautista NS, Solis R, Kamijima O and Ishii T (2001). RAPD, RFLP and SSLP analyses of phylogenetic relationships between cultivated and wild species of rice. Genes Genet. Syst. 76: 71-79.

Collins D, Mill RR and Möller M (2003). Species separation of Taxus baccata, T. canadensis, and T. cuspidata (Taxaceae) and origins of their reputed hybrids inferred from RAPD and cpDNA data. Am. J. Bot. 90: 175-182.

Comes HP and Abbott RJ (2000). Random amplified polymorphic DNA (RAPD) and quantitative trait analyses across a major phylogeographical break in the Mediterranean ragwort Senecio gallicus Vill. (Asteraceae). Mol. Ecol. 9: 61-76.

Ding P, Shao Y, Li Q, Gao J, et al. (2015). The complete chloroplast genome sequence of the medicinal plant Andrographis paniculata. Mitochondrial DNA 2015: 1-2. [Epub ahead of print].

Es Haghi M, Dehghan G, Banihabib N, Zare S, et al. (2014). Protective effects of Cornus mas fruit extract on carbon tetrachloride induced nephrotoxicity in rats. Indian J. Nephrol. 24: 291-296.

Esselman EJ, Crawford DJ, Brauner S, Stuessy TF, et al. (2000). RAPD marker diversity within and divergence among species of Dendroseris (Asteraceae: Lactuceae). Am. J. Bot. 87: 591-596.

Feng K, Wang S, Hu DJ, Yang FQ, et al. (2009). Random amplified polymorphic DNA (RAPD) analysis and the nucleosides assessment of fungal strains isolated from natural Cordyceps sinensis. J. Pharm. Biomed. Anal. 50: 522-526.

Han Y, Jung HW and Park YK (2014). Selective therapeutic effect of Cornus officinalis fruits on the damage of different organs in STZ-induced diabetic rats. Am. J. Chin. Med. 42: 1169-1182.

Hosokawa K, Minami M, Nakamura I, Hishida A, et al. (2005). The sequences of the plastid gene rpl16 and the rpl16-rpl14 spacer region allow discrimination among six species of Scutellaria. J. Ethnopharmacol. 99: 105-108.

Kozyrenko MM, Artiukova EV and Zhuravlev luN (2009). [Independent species status of Iris vorobievii N.S. Pavlova, Iris mandshurica Maxim., and Iris humilis Georgi (Iridaceae): evidence from the nuclear and chloroplast genomes]. Genetika 45: 1575-1584.

Li HJ, Jiang Y and Li P (2009). Characterizing distribution of steroidal alkaloids in Fritillaria spp. and related compound formulas by liquid chromatography-mass spectrometry combined with hierarchical cluster analysis. J. Chromatogr. A. 1216: 2142-2149.

Lu SY, Hong KH, Liu SL, Cheng YP, et al. (2002). Genetic variation and population differentiation of Michelia formosana (Magnoliaceae) based on cpDNA variation and RAPD fingerprints: relevance to post-Pleistocene recolonization. J. Plant Res. 115: 203-216.

Ryuk JA, Kim YS, Lee HW and Ko BS (2014). Identification of Acorus gramineus, A. calamus, and A. tatarinowii using sequence characterized amplified regions (SCAR) primers for monitoring of Acori graminei rhizoma in Korean markets. Int. J. Clin. Exp. Med. 7: 2488-2496.

Sozański T, Kucharska AZ, Szumny A, Magdalan J, et al. (2014). The protective effect of the Cornus mas fruits (cornelian cherry) 
on hypertriglyceridemia and atherosclerosis through PPARa activation in hypercholesterolemic rabbits. Phytomedicine 21: $1774-1784$.

Uzonur I, Akdeniz G, Katmer Z and Ersoy SK (2012). RAPD-PCR and real-time PCR HRM based genetic variation evaluations of Urtica dioica parts, ecotypes and evaluations of morphotypes in Turkey. Afr. J. Tradit. Complement. Altern. Med. 10: 232-245.

Wang T, Su YJ, Li XY, Zheng B, et al. (2004). Genetic structure and variation in the relict populations of Alsophila spinulosa from southern China based on RAPD markers and cPDNA atpB-rbcL sequence data. Hereditas 140: 8-17.

Xin GZ, Lam YC, Maiwulanjiang M, Chan GK, et al. (2014). Authentication of Bulbus Fritillariae Cirrhosae by RAPD-derived DNA markers. Molecules 19: 3450-3459.

Zou LH, Huang JX, Zhang GQ, Liu ZJ, et al. (2015). A molecular phylogeny of Aeridinae (Orchidaceae: Epidendroideae) inferred from multiple nuclear and chloroplast regions. Mol. Phylogenet. Evol. 85: 247-254. 